\title{
Analysis of risk factors for stage I lung adenocarcinoma using low-dose high-resolution computed tomography
}

\author{
RUI FANG ${ }^{1,2^{*}}$, YONG YANG $^{1 *}$, HAICHENG HAN $^{2}$, XIAOQING FU $^{1}$, LIWEN DONG $^{1}$, \\ BAISHENG XIE ${ }^{1}$, WEI LU ${ }^{3}$, CHENYANG MA ${ }^{3}$, FENG CUI ${ }^{1}$, JIAN HU $^{4}$ and JUN WANG ${ }^{5}$ \\ ${ }^{1}$ Guangxing Hospital Affiliated to Zhejiang Chinese Medical University, Hangzhou, Zhejiang 310007; \\ ${ }^{2}$ School of Medicine, Hangzhou Normal University, Hangzhou, Zhejiang 310018; ${ }^{3}$ The Third Clinical Medical College, \\ Zhejiang Chinese Medical University, Hangzhou, Zhejiang 310053; ${ }^{4}$ The First Affiliated Hospital, Zhejiang University, \\ Hangzhou, Zhejiang 310003; ${ }^{5}$ Peking University People's Hospital, Beijing 100044, P.R. China
}

Received March 20, 2018; Accepted May 26, 2018

DOI: $10.3892 / \mathrm{ol} .2018 .8921$

\begin{abstract}
Risk factors for stage I lung adenocarcinoma were analyzed using low-dose high-resolution computed tomography $(\mathrm{CT})$. The patients were divided into case group (stage I lung adenocarcinoma patients) and control group (benign pulmonary nodules patients). All patients were subjected to low-dose high-resolution CT. Multiple linear regression was performed to analyze the CT imaging features of the two groups. Stage I lung adenocarcinoma patients were significantly associated with nodular site $\left(\mathrm{X}_{3}\right.$, upper left lobe) $[95 \% \mathrm{CI}$ (1.796, 54.695), $\mathrm{p}=0.008]$, nodule type $\left(\mathrm{X}_{4}\right)(\mathrm{p}<0.001)$, nodule size $\left(\mathrm{X}_{5}\right)$ [95\% CI $\left.(0.614,0.803), \mathrm{p}<0.001\right]$, spicule sign $\left(\mathrm{X}_{7}\right)$ [95\% CI $(0.029,0.580), \mathrm{p}=0.008]$, lobulation sign $\left(\mathrm{X}_{8}\right)$ [95\% CI (0.048, 0.673), $\mathrm{p}=0.011]$. The stepwise regression equation is: $\operatorname{Logistic}(p)=-12.009+2.294 X_{3}-0.327 X_{4}-0.354 X_{5}-2.042$ $\mathrm{X}_{7}-1.713 \mathrm{X}_{8}$. Risk factors of low-dose and high-resolution CT imaging for patients with stage I lung adenocarcinoma are nodular site (upper left lobe), nodule type, nodule size, spicule sign, and lobulation sign.
\end{abstract}

\section{Introduction}

Malignancy is a common and frequently occurring disease that seriously threatens human health. Malignancy is the second leading cause of death worldwide, and is the first leading cause of death in some countries. In the past several decades, morbidity and mortality rate of lung cancer is the highest among all types of malignancies (1). The incidence of

Correspondence to: Dr Yong Yang, Guangxing Hospital Affiliated to Zhejiang Chinese Medical University, 453 Stadium Road, Hangzhou, Zhejiang 310007, P.R. China

E-mail: yyyg1107@sina.com

*Contributed equally

Key words: stage I lung adenocarcinoma, computed tomography image, risk factors, health care, case-control study lung cancer is expected to be significantly increased not only in developed countries, such as USA, but also in developing countries, such as China (2), exerting enormous pressure on the society (3). According to the lung tumor histological classification established by WHO in 2015, lung cancer originates from epithelial and mesenchymal tissues, and epithelial tissue is the more common origin. Non-small cell lung cancer (NSCLC) accounts for $85 \%$ of lung cancers $(4,5)$. Pulmonary adenocarcinoma is one of the main types of NSCLC. Among patients with lung cancer, prognosis for patients with different TNM clinical stages is significantly different. Early stage (IA-IIB) NSCLC accounts for only $25-30 \%$ of the total number of lung cancers (6). The 5-year survival rate for stage I NSCLC is $73 \%$, whereas for stage IV patients is only $13 \%$ (7). Therefore, early diagnosis of lung adenocarcinoma is particularly important.

At present, low-dose spiral computed tomography (CT), liquid biopsy and fiberoptic bronchoscopy are mainly used for early screening of lung cancer. Traditional serum tumor markers in liquid biopsy have shown certain specificity and sensitivity in the diagnosis of lung cancer, and the combination of several markers can significantly improve the accuracy $(8,9)$, such as CEA, CA125, CA153, and Cyfra21-1, which is more sensitive to the diagnosis of middle and advanced-stage lung cancer. Circulating tumor cells (CTCs) refer to the tumor cells in circulating blood from the primary tumor or metastatic lesions formed by passive migration, invasion or interference of external factors after passive shedding (10). CTCs are present in peripheral blood even in patients with early-stage lung cancer even before the formation of minimal lesions. However, the detection of CTCs is not easy. As an observation in patients with chronic obstructive pulmonary disease (COPD), chest CT and CTCs detection results of 5 patients were compared every year to see if there is a shift from COPD to lung cancer. The results showed that when CTCs were found in the peripheral blood, no small pulmonary nodules were detected on the chest CT scan; the nodules were gradually found by chest CT scan in 1-4 years of subsequent follow-up monitoring, and stage I lung cancer was confirmed by postoperative pathology (11). CTCs can also be used as a joint detection method to distinguish between benign and malignant pulmonary nodules, and the detection rate is higher than that of traditional tumor 
markers (12). At the same time, detection of CTCs can also be used to guide clinical medication and prediction of prognosis $(13,14)$. Detection of circulating tumor nucleic acids, including circulating tumor DNA (ctDNA) and circulating tumor RNA (ctRNA), which were released by tumors into peripheral blood in the early stages of tumorigenesis, can also be used to guide the diagnosis. However, different examination methods provide different results (15).

New bronchoscopic techniques, such as electromagnetic navigation bronchoscopy (ENB), autofluorescence bronchoscopy (AFB) and narrow band imaging (NBI) expanded the diagnostic vision to a certain extent and increased the diagnostic rate of lung cancer (especially early-stage lung cancer). However, novel bronchoscopic techniques include invasive procedures and patients' compliance is poor (16).

With the advantages of convenient operation, reasonable cost, no obvious trauma and side-effects, low-dose spiral CT has been widely used in the early diagnosis of lung cancer $(17,18)$. However, this technique also has some limitations. For example, the false positive rate is high (19). Therefore, combined diagnosis is always needed. For now, it has become a hot research field to analyze the risk factors of stage I lung adenocarcinoma by low-dose high-resolution spiral CT.

\section{Materials and methods}

Subjects. Patients were selected from June 2014 to June 2017 in Guangxing Hospital Affiliated to Zhejiang Chinese Medical University, the First Affiliated Hospital of Zhejiang University (Hangzhou, China), and Peking University People's Hospital (Beijing, China). Patients without complete clinical records and patients younger than 18 years were excluded. The patients were further diagnosed in the Department of Thoracic Surgery in three hospitals, and patients with stage I lung adenocarcinoma were included to serve as case group. At the same time, benign pulmonary nodule patients with similar age and sex distributions were also included to serve as control group.

Diagnostic criteria. Patients in case group (stage I lung adenocarcinoma patients) were diagnosed according to the diagnostic and treatment guidelines for primary lung cancer clinics (2011 edition) established by the Chinese Society of Clinical Oncology (CSCO) (20). TNM staging was performed according to the criteria established by the International Association for the Study of Lung Cancer (IASLC) in 2009: $\mathrm{T} 1 \mathrm{a}$, greatest diameter of tumor $\leq 2 \mathrm{~cm}$; T1b, greatest diameter of tumor $>2$ and $\leq 3 \mathrm{~cm}$; N0, no regional lymph node metastasis; M0, no distant metastasis (21). Patients in control group were diagnosed as benign pulmonary nodules by pathological examination and CT imaging (22).

Inclusion and exclusion criteria. Inclusion criteria: Patients in case group were diagnosed with stage IA and IB lung adenocarcinoma. Patients without serious cardiovascular, digestive and other diseases, without liver and kidney dysfunction, age $>18$ years and $<80$ years, Karnofsky score $>80$ points, volunteered to participate in the study and could cooperate with the researchers. Exclusion criteria: Patients with a history of malignancy, received lobectomy or pneumonectomy, severe infections, severe heart diseases, complicated by liver, kidney and other serious primary diseases, hematopoietic system, nervous system and mental illness, as well as pregnant women were excluded from both case and control group. Patients in control group diagnosed with malignant pulmonary nodules were also excluded.

Data collection. General demographic information (sex, age, ethnicity, marital status and education level) and self-reports of dietary habits, tobacco and alcohol addiction, exercise habits, past history of related diseases and family disease history were collected. All patients were subjected to low-dose high-resolution (512x512 matrix) 128-row 256 iCT imaging.

Ethics approval. This study was approved by the Ethics Committee (approval no. 2014LL001) of Guangxing Hospital Affiliated to Zhejiang Chinese Medical University (Hangzhou, China). Signed informed consents were obtained from the patients or the guardians.

Statistical analyses. $\chi^{2}$ test was used to determine the baseline of the two groups of subjects. Continuous variables were compared by using ANOVA; Dunnett's method was used when the variance was homogeneous, and Mann-Whitney $\mathrm{U}$ test was used when the variance was not homogeneous in comparison between two groups. Multivariate correlation analysis was performed by using logistic regression analysis. Logistic regression analysis of malignancy probability, nodule size and percentage of solid nodules in patients with stage I lung adenocarcinoma were performed by using $\mathrm{R}$ language. ROC curve was drawn and AUC was calculated to evaluate the diagnostic value of the nodular site $\left(\mathrm{X}_{3}\right)$, nodule type $\left(\mathrm{X}_{4}\right)$, nodule size $\left(\mathrm{X}_{5}\right)$, spicule sign $\left(\mathrm{X}_{7}\right)$, lobulation sign $\left(\mathrm{X}_{8}\right)$ to lung adenocarcinoma status. The sensitivity and specificity were calculated according to the cut-off value.

\section{Results}

General information. Case group included 82 males and 112 females, with an average age of 57.54 years. Control group included 44 males and 46 females, with an average age of 56.28 years. After examination, no significant differences in sex, age, ethnicity, marital status and educational level were found between case and control group (Table I).

Logistic regression analysis. Logistic regression analysis was performed by using stage I lung adenocarcinoma ( $1=$ stage IA and IB lung adenocarcinoma, $0=$ benign pulmonary nodules) as dependent variable, and low-dose high-resolution CT imaging features including nodule type, nodule size, vacuolar sign, bronchial inflatable sign, bronchial truncated sign, smooth sign, spicule sign, lobulated sign and pleural indentation as independent variables. Using stepwise regression, equation for the final model showed that stage I lung adenocarcinoma was associated with nodular site $\left(\mathrm{X}_{3}\right.$, upper left lobe) [95\% CI $(1.796,54.695), \mathrm{p}=0.008]$, nodule type $\left(\mathrm{X}_{4}\right)$ $(\mathrm{p}<0.001)$, nodule size $\left(\mathrm{X}_{5}\right)$ [95\% CI $\left.(0.614,0.803), \mathrm{p}<0.001\right]$, spicule sign $\left(\mathrm{X}_{7}\right)$ [95\% CI $\left.(0.029,0.580), \mathrm{p}=0.008\right]$ and lobulation sign $\left(\mathrm{X}_{8}\right)$ [95\% CI $\left.(0.048,0.673), \mathrm{p}=0.011\right]$ (Table II). Stepwise regression equation is: $\operatorname{Logistic}(\mathrm{p})=-12.009+2.294$ $\mathrm{X}_{3}-0.327 \mathrm{X}_{4}-0.354 \mathrm{X}_{5}-2.042 \mathrm{X}_{7}-1.713 \mathrm{X}_{8}$. Logistic regression 
Table I. Comparison of the basic information between two groups.

\begin{tabular}{|c|c|c|c|c|c|}
\hline Variables & Cases & $\begin{array}{l}\text { Case group } \\
\quad(n=194)\end{array}$ & $\begin{array}{l}\text { Control group } \\
\qquad(\mathrm{n}=90)\end{array}$ & $\chi^{2}$ value & P-value \\
\hline \multicolumn{6}{|l|}{ Sex } \\
\hline Male & 126 & 82 & 44 & \multirow[t]{2}{*}{1.092} & \multirow[t]{2}{*}{0.296} \\
\hline Female & 158 & 112 & 46 & & \\
\hline \multicolumn{6}{|l|}{ Age (years) } \\
\hline$<60$ & 153 & 101 & 52 & \multirow[t]{2}{*}{0.808} & \multirow[t]{2}{*}{0.369} \\
\hline$\geq 60$ & 131 & 93 & 38 & & \\
\hline \multicolumn{6}{|l|}{ Ethnicity } \\
\hline Han nationality & 267 & 183 & 84 & \multirow[t]{2}{*}{0.108} & \multirow[t]{2}{*}{0.742} \\
\hline Minority & 17 & 11 & 6 & & \\
\hline \multicolumn{6}{|l|}{ Marriage status } \\
\hline Married & 258 & 178 & 80 & \multirow[t]{2}{*}{0.606} & \multirow[t]{2}{*}{0.436} \\
\hline Unmarried and divorced & 26 & 16 & 10 & & \\
\hline \multicolumn{6}{|l|}{ Degree of education } \\
\hline Junior high school and below & 151 & 104 & 57 & \multirow[t]{3}{*}{2.482} & \multirow[t]{3}{*}{0.289} \\
\hline $\begin{array}{l}\text { High school, technical secondary } \\
\text { school and college }\end{array}$ & 74 & 55 & 19 & & \\
\hline College and above & 49 & 35 & 14 & & \\
\hline \multicolumn{6}{|l|}{ Smoking } \\
\hline Yes & 85 & 56 & 29 & \multirow[t]{2}{*}{0.330} & \multirow[t]{2}{*}{0.566} \\
\hline No & 199 & 138 & 61 & & \\
\hline \multicolumn{6}{|l|}{ Family history of cancer } \\
\hline Yes & 52 & 35 & 17 & \multirow[t]{2}{*}{0.030} & \multirow[t]{2}{*}{0.864} \\
\hline No & 232 & 159 & 73 & & \\
\hline
\end{tabular}

Table II. Logistic regression analysis of low-dose high-resolution CT imaging features on stage I lung adenocarcinoma.

\begin{tabular}{|c|c|c|c|c|c|c|c|}
\hline Variables & Types & B & SE & Wald & Odd ratio & $95 \% \mathrm{CI}$ & P-value \\
\hline Smoking $\left(\mathrm{X}_{1}\right)$ & & 0.738 & 0.560 & 1.739 & 2.093 & $0.698-6.271$ & 0.187 \\
\hline $\begin{array}{l}\text { Family history } \\
\text { of cancer }\left(\mathrm{X}_{2}\right)\end{array}$ & & -1.042 & 0.736 & 2.007 & 0.353 & $0.083-1.491$ & 0.157 \\
\hline \multirow[t]{4}{*}{ Nodular site $\left(\mathrm{X}_{3}\right)$} & Left upper lobe & 2.294 & 0.872 & 6.925 & 9.910 & $1.796-54.695$ & 0.008 \\
\hline & Left lower lobe & 0.049 & 1.166 & 0.002 & 1.050 & $0.107-10.334$ & 0.996 \\
\hline & Right upper lobe & 1.240 & 0.832 & 2.223 & 3.455 & $0.677-17.633$ & 0.136 \\
\hline & Right middle lobe & 2.164 & 0.899 & 5.794 & 8.708 & $1.495-50.726$ & 0.016 \\
\hline \multirow[t]{3}{*}{ Nodule type $\left(\mathrm{X}_{4}\right)$} & & & & 44.188 & & & $<0.001$ \\
\hline & Partial solid nodules & 24.995 & $27,265.515$ & 0.001 & 0.001 & 0.001 & 0.999 \\
\hline & Solid nodules & 21.016 & $27,265.515$ & 0.001 & 0.001 & 0.001 & 0.999 \\
\hline \multirow[t]{5}{*}{ Nodule size $\left(\mathrm{X}_{5}\right)$} & & 19.901 & $27,265.515$ & 0.001 & 0.001 & 0.001 & 0.999 \\
\hline & $\begin{array}{l}\text { Purely ground glass-like } \\
\text { density nodules }\end{array}$ & -0.354 & 0.069 & 26.443 & 0.702 & $0.614-0.803$ & $<0.001$ \\
\hline & Bronchial inflatable sign $\left(\mathrm{X}_{6}\right)$ & -1.326 & 0.749 & 3.129 & 0.266 & $0.061-1.154$ & 0.077 \\
\hline & Burr sign $\left(\mathrm{X}_{7}\right)$ & -2.042 & 0.764 & 7.143 & 0.130 & $0.029-0.580$ & 0.008 \\
\hline & Lobulation sign $\left(\mathrm{X}_{8}\right)$ & -1.713 & 0.672 & 6.495 & 0.180 & $0.048-0.673$ & 0.011 \\
\hline Constant & & -20.009 & - & 0.001 & 0.001 & & 0.999 \\
\hline
\end{tabular}


Table III. The sensitivity and specificity of $\mathrm{CT}$ imaging risk factors in the diagnosis of stage I lung adenocarcinoma in the predictive model.

\begin{tabular}{lccccccccc}
\multirow{2}{*}{$\begin{array}{l}\text { Test result } \\
\text { variables }\end{array}$} & $\begin{array}{c}\text { Area under } \\
\text { the curve }\end{array}$ & $\mathrm{SE}^{\mathrm{a}}$ & $\begin{array}{c}\text { Asymptotic } \\
\text { sig }^{\mathrm{b}}\end{array}$ & & Lower bound & Upper bound & Sensitivity & 1-Sensitivity & $\begin{array}{c}\text { Youden } \\
\text { index }\end{array}$ \\
\hline Nodular site $\left(\mathrm{X}_{3}\right)$ & 0.678 & 0.067 & 0.015 & 0.545 & 0.810 & 0.663 & 0.316 & 0.347 \\
Nodule type $\left(\mathrm{X}_{4}\right)$ & 0.821 & 0.063 & 0.001 & 0.697 & 0.945 & 0.926 & 0.316 & 0.611 \\
Nodule size $\left(\mathrm{X}_{5}\right)$ & 0.702 & 0.063 & 0.006 & 0.579 & 0.825 & 0.800 & 0.474 & 0.326 \\
Spicule sign $\left(\mathrm{X}_{7}\right)$ & 0.600 & 0.069 & 0.170 & 0.465 & 0.735 & 0.463 & 0.263 & 0.200 \\
Lobulation sign $\left(\mathrm{X}_{8}\right)$ & 0.616 & 0.064 & 0.112 & 0.490 & 0.742 & 0.337 & 0.105 & 0.232
\end{tabular}

The test result variables: predicted probability, predicted. ${ }^{a}$ Under the non-parament assumption; ${ }^{b}$ null hypathesis: true area, 0.5 . CT, computed tomography.

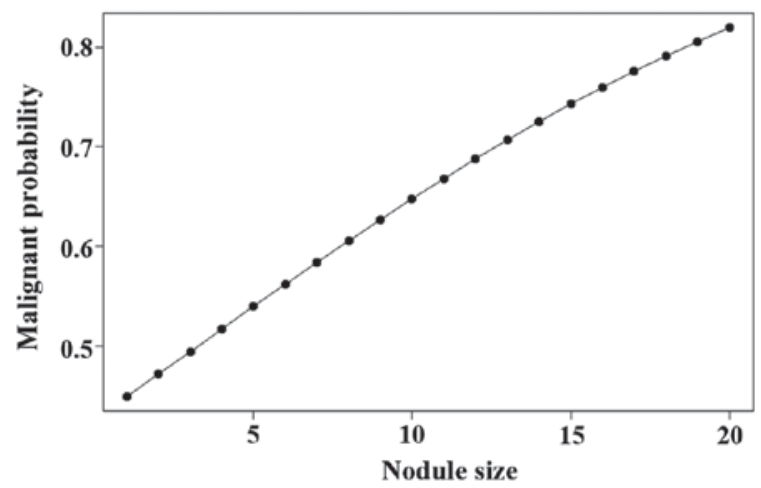

Figure 1. Logistic regression analysis of malignant probability and nodule size in stage I lung adenocarcinoma patients.

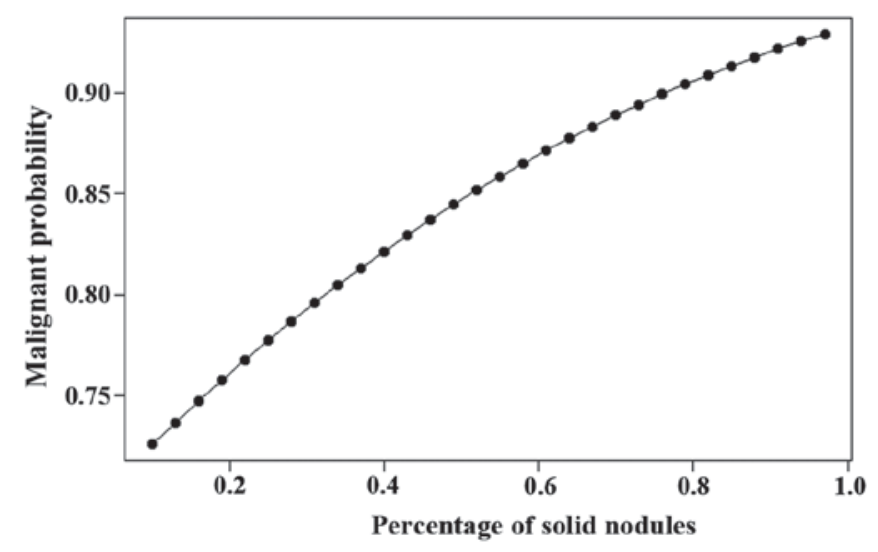

Figure 2. Logistic regression analysis of the percentage of malignant and solid nodules in stage I lung adenocarcinoma patients.

analysis of malignant probability, nodule size, and solid nodule percentage in patients with stage I lung adenocarcinoma are shown in Figs. 1 and 2.

The diagnostic value of CT imaging risk factors to stage I lung adenocarcinoma in the predictive model. The AUC of nodular site $\left(\mathrm{X}_{3}\right)$, nodule type $\left(\mathrm{X}_{4}\right)$, nodule size $\left(\mathrm{X}_{5}\right)$, spicule sign $\left(\mathrm{X}_{7}\right)$, lobulation sign $\left(\mathrm{X}_{8}\right)$ were respectively $0.678(0.545-0.810)$, 0.821 (0.697-0.945), $0.702(0.579-0.825), 0.600(0.465-0.735)$

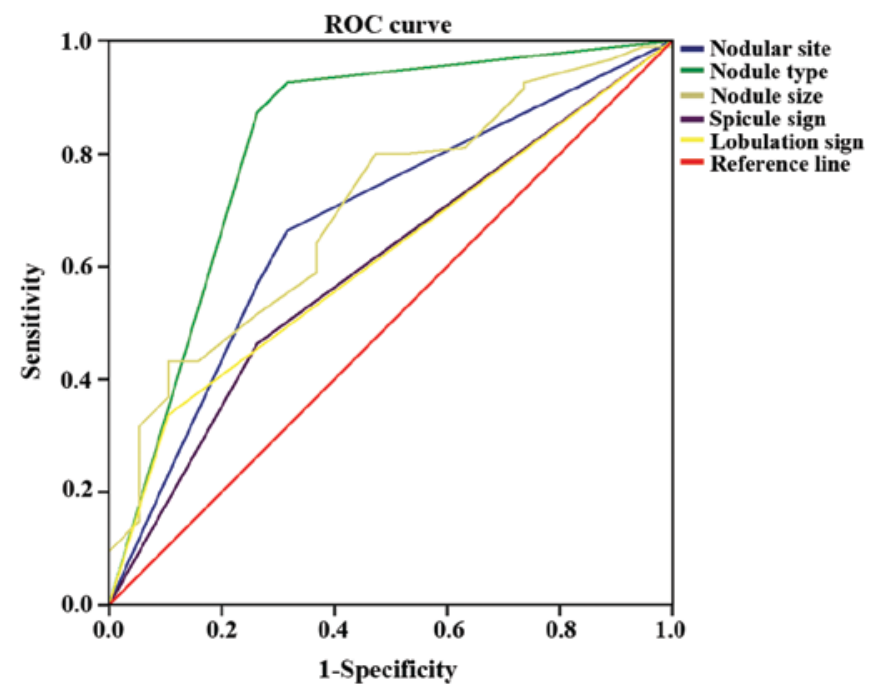

Figure 3. ROC curve of different CT imaging risk factors to stage I lung adenocarcinoma in the predictive model. CT, computed tomography.

and $0.616(0.490-0.742)$. The sensitivity and specificity of nodular site $\left(\mathrm{X}_{3}\right)$, nodule type $\left(\mathrm{X}_{4}\right)$, nodule size $\left(\mathrm{X}_{5}\right)$, spicule sign $\left(\mathrm{X}_{7}\right)$, lobulation sign $\left(\mathrm{X}_{8}\right)$ in the diagnosis of stage $\mathrm{I}$ lung adenocarcinoma were 66.3 and $31.6 \%, 92.6$ and $31.6 \%$, 80 and $47.4 \%, 46.3$ and $26.3 \%, 33.7$ and $10.5 \%$, respectively (Table III and Fig. 3).

\section{Discussion}

Early lung cancer usually has no typical symptoms, but it can be detected as pulmonary nodules in imaging. The nodules in $\mathrm{CT}$ imaging or chest X-ray are $<30 \mathrm{~mm}$ in diameter with round or irregular shape and show high density shadow, the border is clear or unclear (23). With the development of imaging technology, low-dose high-resolution CT imaging has gradually become the primary means of early screening of lung cancer, and different screening guidelines, such as National Comprehensive Cancer Network (NCCN) and the American College of Chest Physicians (ACCP) $(24,25)$, have been established by different academic organizations. Based on the characteristics of Asian people, guidelines for the 
assessment of patients with pulmonary nodules were established in February 2016 (26). Subsequently, guidelines for the classification, diagnosis and treatment of pulmonary nodules has also been updated (2016 edition) in China (27). Those guidelines all suggest that the characteristics of lung CT and risk factors of the patients shall be screened. Age and smoking history were mentioned as a potential factor for lung cancer, however, the morbidity prediction model and the follow-up were different in these guidelines.

Studies on the lung cancer prediction model have a history of $>20$ years, and the earliest model was the Mayo model proposed in 1997. The area under the ROC curve $(>0.75)$ in Mayo model has been verified by multiple external verifications, this model is currently the most widely used prediction model (28). In recent years, many scholars have put forward relevant prediction models based on the results of their own clinical studies, such as the VA model, and the Brock University model $(29,30)$. Among them, the accuracy of Brock University model is the highest due to the large data included, and the area under the ROC curve can reach at least 0.94 . For Chinese population, the relatively mature model is Peking University model (31). Because the sample size and risk factors included in each model are different, reported accuracy is not the same. Therefore, it is important to combine the epidemiological characteristics of lung cancer in various regions, establish a corresponding prediction model for the guidance of local lung cancer treatment.

According to their internal density, pulmonary nodules are simply divided into solid, partial solid and ground glass density nodules. Solid nodules are nodules with uniform soft tissue density, the density is uniform, and the blood vessel and bronchial images are covered during the period. Partial solid nodules refer to the nodules that contain both ground glass density and solid soft tissue density. Ground glass density nodules refer to vague nodules in the lungs, with nodular density slightly increased compared to the surrounding lung parenchyma, but the profile of the internal blood vessels and bronchi are still visible (32). Ground glass density nodules are non-specific imaging manifestations that can be caused by a variety of pathologies including inflammation, and atypical adenomatous hyperplasia. Highest degree of malignancy was observed in partial solid nodules, followed by ground glass density nodules and solid nodules.

Some researchers believe that the diameter of partial solid nodules is positively correlated with the degree of malignancy. In the 2013 version of ACCP, the recommended treatment path for solid nodules is as follows: For partial solid pulmonary nodules with a diameter $\leq 8 \mathrm{~mm}$, CT should be routinely performed, and non-surgical biopsy or surgical treatment should be performed immediately in the case of enlargement. For partial solid pulmonary nodules with a diameter $>8 \mathrm{~mm}$, CT should be performed at 3 months after the initial examination, and PET scan, non-surgical biopsy and surgical treatment should be performed actively if lesion persists. For partial solid pulmonary nodules with a diameter $>15 \mathrm{~mm}$, active treatment should be performed immediately (33). As a result, the greater the partial diameter of partial solid nodules is, the higher the risk of malignancy will be. This study also draws similar conclusions (Fig. 2).

The size of pulmonary nodules and its pathological properties are closely correlated with each other. Some studies even concluded that the size of the diameter is an independent risk factor for the diagnosis of benign and malignant lesions, while the diameter of benign nodules is relatively small, and consistent findings were also found in this study. Occurrence of lung cancer includes a series of stages of tumor growth including hyperplasia, atypical hyperplasia, carcinoma in situ and invasive cancer (34). This study shows that the size of the nodules is closely related to the degree of malignancy, the larger the nodules, the higher the degree of malignancy (Fig. 1). This shows that follow-up is crucial, and some guidelines suggest that follow-up is not necessary for nodules with a diameter $<6 \mathrm{~mm}$, but the results of this study show that attention should also be paid to some nodules with small diameters.

Characteristics of the pulmonary nodules are also important basis for the judgement of the nature of nodules. Due to differences in the growth rate of various cells in malignant pulmonary nodules, or bronchial and vascular blockage of the growth of cancer cells, CT morphological lobulation symptoms arise (35). Lobulation sign is positively correlated with the growth rate of cells and degree of malignancy (36). Spicule sign is caused by the infiltration of tumor into adjacent bronchus, sheath or local lymph node. Lobulation sign is also a characteristic of malignant pulmonary nodules (31). Bronchial inflatable sign is caused by the growth of tumor cells attached to the wall, and alveolar bronchia is still preserved in lesions; at the same time, the tumor cells and peripheral fibrous tissue proliferate, and the bronchiectasis is formed (37). Bronchial inflatable sign is common in malignant tumors, but can also be observed in benign tumors (38). This study also showed that spicule and lobulation sign were closely correlated with pathological features.

Incidence of lung cancer is different in different sites. In terms of lung adenocarcinoma, most cases were found in upper lung lobes (39). This study also showed that stage I lung adenocarcinoma mainly affected upper left lung, followed by upper right lung. However, the mechanism remains unclear.

In conclusion, in this study, the risk factors of disease were combined with CT imaging characteristics of pulmonary nodules to diagnose stage I lung adenocarcinoma. The subjects were with pulmonary nodules but without obvious symptoms. Therefore, our study achieved early diagnosis and treatment. Results show that the size of nodules is closely correlated with the incidence of stage I lung adenocarcinoma. With the increase of the diameter of pulmonary nodules, the possibility of malignancy increases. For smaller nodules, their own risk factors should be combined for follow-up. The nature inside the nodules is correlated with the degree of malignancy, and highest malignancy was observed in partial solid nodules. Lobulation and spicule signs are typical manifestations of early lung adenocarcinoma, and the probability of malignancy is relatively high for bronchial inflatable sign. In addition, incidence of stage I lung adenocarcinoma also showed predilection in the left upper lung. The sample size in this study is small, and most patients were from local region. Future studies with larger sample size are needed to further confirm the conclusion. Our future study will try to combine liquid biopsy to identify the risk factors for stage I lung adenocarcinoma , and establish a more reliable disease prediction model, so as to improve the diagnosis and treatment of this disease. 


\section{Acknowledgements}

Not applicable.

\section{Funding}

This study was supported by the Science and Technology Project of Zhejiang Province (Major Science and Technology Program) (no. 2013C03044-3), and the Agricultural and Social Development Scientific Research Program of Hangzhou (no. 20180417A03).

\section{Availability of data and materials}

The datasets used and/or analyzed during the present study are available from the corresponding author on reasonable request.

\section{Authors' contributions}

RF, YY, HH, XF and LD conceived and designed the study. BX, WL, CM, FC, JH and JW collected, analyzed and interpreted the patient data. RF and YY wrote the manuscript. BX, $\mathrm{JH}$ and $\mathrm{JW}$ revised the manuscript for important intellectual content. All authors read and approved the final manuscript.

\section{Ethics approval and consent to participate}

The study was approved by the Ethics Committee of Guangxing Hospital Affiliated to Zhejiang Chinese Medical University (Hangzhou, China). Patients who participated in this research had complete clinical data. Signed informed consents were obtained from the patients.

\section{Patient consent for publication}

Not applicable.

\section{Competing interests}

The authors declare that they have no competing interests.

\section{References}

1. Ferlay J, Soerjomataram I, Dikshit R, Eser S, Mathers C, Rebelo M, Parkin DM, Forman D and Bray F: Cancer incidence and mortality worldwide: Sources, methods and major patterns in GLOBOCAN 2012. Int J Cancer 136: E359-E386, 2015.

2. Wu F, Lin GZ and Zhang JX: An overview of cancer incidence and trend in China. Chin Cancer 21: 81-85, 2012

3. Torre LA, Bray F, Siegel RL, Ferlay J, Lortet-Tieulent J and Jemal A: Global cancer statistics, 2012. CA Cancer J Clin 65: 87-108, 2015

4. Brawley OW: Avoidable cancer deaths globally. CA Cancer J Clin 61: 67-68, 2011

5. Zhang R, Zhang Y, Wen F, Wu K and Zhao S: Analysis of pathological types and clinical epidemiology of 6,058 patients with lung cancer. Zhongguo Fei Ai Za Zhi 19: 129-135, 2016 (In Chinese).

6. Scott WJ, Howington J, Feigenberg S, Movsas B and Pisters K; American College of Chest Physicians: Treatment of non-small cell lung cancer stage I and stage II: ACCP evidence-based clinical practice guidelines (2nd edition). Chest 132 (3 Suppl): 234S-242S, 2007.

7. Woodard GA, Jones KD and Jablons DM: Lung cancer staging and prognosis. Cancer Treat Res 170: 47-75, 2016.
8. Lee JH and Chang JH: Diagnostic utility of serum and pleural fluid carcinoembryonic antigen, neuron-specific enolase, and cytokeratin 19 fragments in patients with effusions from primary lung cancer. Chest 128: 2298-2303, 2005.

9. Okamura K, Takayama K, Izumi M, Harada T, Furuyama K and Nakanishi Y: Diagnostic value of CEA and CYFRA 21-1 tumor markers in primary lung cancer. Lung Cancer 80: 45-49, 2013.

10. Lin M, Chen J-F, Lu Y-T, Zhang Y, Song J, Hou S, Ke Z and Tseng H-R: Nanostructure embedded microchips for detection, isolation, and characterization of circulating tumor cells. Acc Chem Res 47: 2941-2950, 2014.

11. Ilie M, Hofman V, Long-Mira E, Selva E, Vignaud JM, Padovani B, Mouroux J, Marquette CH and Hofman P: 'Sentinel' circulating tumor cells allow early diagnosis of lung cancer in patients with chronic obstructive pulmonary disease. PLoS One 9: e111597, 2014.

12. Chen YY and Xu GB: Erratum to: Effect of circulating tumor cells combined with negative enrichment and CD45-FISH identification in diagnosis, therapy monitoring and prognosis of primary lung cancer. Med Oncol 31: 240, 2014.

13. Gorges TM, Penkalla N, Schalk T, Joosse SA, Riethdorf S, Tucholski J, Lücke K, Wikman H, Jackson S, Brychta N, et al: Enumeration and molecular characterization of tumor cells in lung cancer patients using a novel in vivo device for capturing circulating tumor cells. Clin Cancer Res 22: 2197-2206, 2016

14. Chen X, Wang X, He H, Liu Z, Hu JF and Li W: Combination of circulating tumor cells with serum carcinoembryonic antigen enhances clinical prediction of non-small cell lung cancer. PLoS One 10: e0126276, 2015.

15. Hulbert A, Jusue-Torres I, Stark A, Chen C, Rodgers K, Lee B, Griffin C, Yang A, Huang P, Wrangle J, et al: Early detection of lung cancer using DNA promoter hypermethylation in plasma and sputum. Clin Cancer Res 23: 1998-2005, 2017.

16. Iftikhar IH and Musani AI: Narrow-band imaging bronchoscopy in the detection of premalignant airway lesions: A meta-analysis of diagnostic test accuracy. Ther Adv Respir Dis 9: 207-216, 2015.

17. Garg K, Keith RL, Byers T, Kelly K, Kerzner AL, Lynch DA and Miller YE: Randomized controlled trial with low-dose spiral CT for lung cancer screening: Feasibility study and preliminary results. Radiology 225: 506-510, 2002.

18. Ettinger DS, Wood DE, Akerley W, Bazhenova LA, Borghaei H, Camidge DR, Cheney RT, Chirieac LR, D'Amico TA, Demmy TL, et al: Non-small cell lung cancer, version 1.2015. J Natl Compr Canc Netw 12: 1738-1761, 2014.

19. Croswell JM, Baker SG, Marcus PM, Clapp JD and Kramer BS: Cumulative incidence of false-positive test results in lung cancer screening: A randomized trial. Ann Intern Med 152: 505-512, W176-W180, 2010.

20. Zhi X, Wu Y, Ma S, Wang T, Wang C, Wang J, Shi Y, Lu Y, Liu L, Liu D, et al: Chinese guidelines on the diagnosis and treatment of primary lung cancer (2011 version). Zhongguo Fei Ai Za Zhi 15: 677-688, 2012 (In Chinese).

21. Vallières E, Shepherd FA, Crowley J, Van Houtte P, Postmus PE, Carney D, Chansky K, Shaikh Z and Goldstraw P; International Association for the Study of Lung Cancer International Staging Committee and Participating Institutions: The IASLC Lung Cancer Staging Project: Proposals regarding the relevance of TNM in the pathologic staging of small cell lung cancer in the forthcoming (seventh) edition of the TNM classification for lung cancer. J Thorac Oncol 4: 1049-1059, 2009.

22. Tsushima Y, Tateishi U, Uno H, Takeuchi M, Terauchi T, Goya T and Kim EE: Diagnostic performance of PET/CT in differentiation of malignant and benign non-solid solitary pulmonary nodules. Ann Nucl Med 22: 571-577, 2008.

23. Hansell DM, Bankier AA, MacMahon H, McLoud TC, Müller NL and Remy J: Fleischner Society: Glossary of terms for thoracic imaging. Radiology 246: 697-722, 2008.

24. Wood DE: National Comprehensive Cancer Network (NCCN) Clinical practice guidelines for lung cancer screening. Thorac Surg Clin 25: 185-197, 2015.

25. Gould MK, Fletcher J, Iannettoni MD, Lynch WR, Midthun DE, Naidich DP and Ost DE; American College of Chest Physicians: Evaluation of patients with pulmonary nodules: When is it lung cancer?: ACCP evidence-based clinical practice guidelines (2nd edition). Chest 132 (3 Suppl): 108S-130S, 2007.

26. Kim YK, Lee SH, Seo JH, Kim JH, Kim SD and Kim GK: A comprehensive model of factors affecting adoption of clinical practice guidelines in Korea. J Korean Med Sci 25: 1568-1573, 2010. 
27. Zhou Q, Fan Y, Wang Y, Qiao Y, Wang G, Huang Y, Wang X, Wu N, Zhang G, Zheng X, et al: [China National Guideline of Classification, Diagnosis and Treatment for Lung Nodules (2016 version)].Zhongguo Fei Ai Za Zhi 19: 793-798, 2016 (In Chinese).

28. Swensen SJ, Silverstein MD, Ilstrup DM, Schleck CD and Edell ES: The probability of malignancy in solitary pulmonary nodules. Application to small radiologically indeterminate nodules. Arch Intern Med 157: 849-855, 1997.

29. Gould MK, Ananth L and Barnett PG; Veterans Affairs SNAP Cooperative Study Group: A clinical model to estimate the pretest probability of lung cancer in patients with solitary pulmonary nodules. Chest 131: 383-388, 2007.

30. McWilliams A, Tammemagi MC, Mayo JR, Roberts H, Liu G, Soghrati K, Yasufuku K, Martel S, Laberge F, Gingras M, et al: Probability of cancer in pulmonary nodules detected on first screening CT. N Engl J Med 369: 910-919, 2013.

31. Li Y, Chen KZ and Wang J: Development and validation of a clinical prediction model to estimate the probability of malignancy in solitary pulmonary nodules in Chinese people. Clin Lung Cancer 12: 313-319, 2011.

32. Wormanns D and Hamer OW: Glossary of terms for thoracic imaging - German version of the Fleischner Society Recommendations. ROFO 187: 638-661, 2015 (In German).

33. Ost DE and Gould MK: Decision making in patients with pulmonary nodules. Am J Respir Crit Care Med 185: 363-372, 2012.

34. Aoki T, Nakata H, Watanabe H, Nakamura K, Kasai T, Hashimoto $\mathrm{H}$, Yasumoto $\mathrm{K}$ and Kido M: Evolution of peripheral lung adenocarcinomas: CT findings correlated with histology and tumor doubling time. AJR Am J Roentgenol 174: 763-768, 2000 .
35. Patel VK, Naik SK, Naidich DP, Travis WD, Weingarten JA Lazzaro R, Gutterman DD, Wentowski C, Grosu HB and Raoof S: A practical algorithmic approach to the diagnosis and management of solitary pulmonary nodules: part 2: pretest probability and algorithm. Chest 143: 840-846, 2013.

36. Ost D, Fein AM and Feinsilver SH: Clinical practice. The solitary pulmonary nodule. N Engl J Med 348: 2535-2542, 2003.

37. Haro A, Yano T, Kohno M, Yoshida T, Okamoto T and Maehara Y: Ground-glass opacity lesions on computed tomography during postoperative surveillance for primary non-small cell lung cancer. Lung Cancer 76: 56-60, 2012.

38. Oda S, Awai K, Murao K, Ozawa A, Yanaga Y, Kawanaka K and Yamashita Y: Computer-aided volumetry of pulmonary nodules exhibiting ground-glass opacity at MDCT. AJR Am J Roentgenol 194: 398-406, 2010.

39. Collisson EA, Campbell JD, Brooks AN, Berger AH, Lee W, Chmielecki J, Beer DG, Cope L, Creighton CJ, Danilova L, et al; Cancer Genome Atlas Research Network: Comprehensive molecular profiling of lung adenocarcinoma. Nature 511: 543-550, 2014.

This work is licensed under a Creative Commons Attribution-NonCommercial-NoDerivatives 4.0 International (CC BY-NC-ND 4.0) License. 